\title{
ANALISIS ALIH KODE DALAM DIKSI DEBAT DAN PRESENTASI PENGAMAT POLITIK ROCKY GERUNG
}

\author{
SUNARA \\ Pendidikan Bahasa Inggris, FKIP, Universitas Subang \\ rasunaok@gmail.com
}

\begin{abstract}
ABSTRAK
Penelitian ini bertujuan untuk mengetahui pengambilan diksi alih kode bahasa Indonesia kedalam bahasa Inggris yang dilakukan oleh pengamat politik Rocky Gerung dalam setiap debat dan presentasi di berbagai media visual. Perubahan diksi terjadi pada bahasa sumber bahasa Indonesia menjadi diksi bahasa sasaran bahasa Inggris menyebabkan terjadinya alih kode. Pengamat politik Rocky Gerung dalam pengambilan diksi alih kode bahasa Inggris untuk mempresentasikan maksud memiliki beberapa tujuan misalnya untuk berkomunikasi yang indah dan tidak membosankan serta menarik untuk didengar, memiliki tujuan sebagai analogi, membandingkan, menggambarkan keadaan yang sebenarnya dengan kalimat lain yang memiliki analogi sama. Alih Kode Rocky Gerung juga memiliki rasa bahasa yang biasa saja, dia memilihnya bahasa Inggris untuk menguatkan rasa bahasa dan gampang diingat, membuat ungkapan yang efektif dan hemat dalam pengambilan diksi alih kode, menekankan, dan mempertahankan warna asli bahasa tersebut, memperhatikan kejiwaan agar makna diksi yang diucapkan lebih mengena dan mendalam, atau secara suka suka ia ungkapkan dengan diksi bahasa Inggris sambil tertawa dan bercanda, atau sebagai argumentasi untuk menarik simpatik pendengar sehingga menjadi menarik. Rocky Gerung memang memiliki bakat berbahasa dan pengetahuan yang cukup. Peneliti menggunakan teori sosiolinguistik alih kode. Metode analisis yang digunakan adalah analisis alih kode yang difokuskan pada aspek kebahasaan terkait dengan aspek sosial data yang berupa suara dari presentasi dan debat dikumpulkan dari media YouTube dan dianalisis dengan menggunakan model alih kode yang diungkapkan situasi dan maksud tujuan tertentu. Rocky sering memberikan penjelasan kepada lawan bicara melalui audio visual dalam bentuk seminar atau debat yang diselenggarakan beberapa televisi swasta. Para hadirin menyaksikan debat dan presentasinya dari berbagai lapisan akademisi, ahli hukum, mahasiswa dan rakyat biasa yang menonton dari layar televisi media visual. Dari pengamatan observasi variasi bahasa dan tipe penggunaan diksi rekaman video yang baik dan menarik di YouTube telah mendorong netizen untuk berpartisipasi memberikan komentar beragam dan menarik secara politik, social, budaya, ekonomi dan linguistic.
\end{abstract}

Kata kunci: Bahasa Konsep Politik, Analisis Alih Kode

\section{A. PENDAhuluan}

Bahasa Inggris adalah bahasa internasional. Banyak orang menggunakan bahasa tersebusebagai t baik sebagai bahasa sehari hari maupun sebagai sekedar alih kode (code switch) karena lebih singkat dan representative. Orang menggunakan bahasa melalui komunikasi satu sama lain. Bahasa Inggris bukan 
lagi hanya sebagai bahasa komunikasi tetapi sebagai bahasa ilmiah karena kepadatan dan sedikit hurufnya namun luas maknanya. Sebagai alat untuk menyampaikan informasi berupa gagasan, maksud dan perasaan secara langsung, pemilihan kosa kata atau diksi menjadi hal penting agar suatu kata menjadi lebih bermakna. Penggunaan alih kode dalam berbahasa bisa terjadi karena faktor suka tidak suka, bakat, penguasaan dua budaya bahasa yang luas, pemenuhan kebutuhan berbahasa, keakraban sesama pengguna bahasa, atau salah satu cara untuk mengatasi kebekuan pemilihan kosakata karena suatu kata dalam bahasa tertentu kesulitan dicari padanannya pada saat berbicara. Dalam perspektif linguistik alih kode adalah bagian dari fenomena kontak bahasa dengan beragam tujuan dan kepentingan.

Menurut Cantone dalam Arifin dan lafasau (2016) percampuran bahasa tidak harus dilihat sebagai suatu kekurangan kompetensi penuturnya. Gumperz (1987) membedakan alih kode situasional, alih kode metafora yang berimplikasi pada pilihan kosa kata dan bahasa untuk mencapai efek komunikatif khusus. Penomena alih kode adalah pilihan kosa kata atau bahasa yang dapat berubah dalam satu wacana. Rocky Gerung, sebagai pengamat politik, menggunakan terminologi yang berbeda untuk data yang intinya sama dari bahasa asal yang dia ucapkan ke bahasa lain pada saat yang sama, tetapi dalam kasus lain dia ungkapkan kosa kata dengan makna yang berbeda sama sekali pada penomena lain. Alih kode adalah penomena kebahasaan atas kemampuan penutur bilingual untuk berkomunikasi dalam dua bahasa atau lebih yang dikuasainya. Pembicara alih kode harus mampu mengintegrasikan struktur dua bahasa yang dikuasainya walaupun dipandang 'miring' dan mungkin tidak dipahami oleh pengamat lain karena tidak pada jalurnya. Itu adalah cerminan struktur sosial dan mekanisme kognitif secara linguistik yang memiliki tujuan dan kepentingan. Beralih kode bisa digunakan dengan beberapa ungkapan prasa, juga berupa sisipan kata karena faktor sosial dan situasi komunikasi. Untuk menangani penomena yang berbeda, penarikan kesimpulan juga kadang dilakukan melalui alih kode. Mengungkapkan rasa bahasa dari dua bahasa yang berbeda juga dimunculkan dalam alih kode. Dalam hal ini Rocky Gerung adalah pendanda bahwa ia seorang akademisi yang mengekspresikan dalam tataran budaya dan sosial. Sankoff dalam Arifin dan Lafasau (2016) beralih kode dianggap sebagai hal bergengsi seperti di Papua Nugini penduduknya yang menguasai tiga bahasa Buang, Tok Pisin, dan Yabem dan diharapkan dari orang yang berkuasa atau berpengaruh di masyarakat. Singapura memiliki 4 bahasa resmi : bahasa Inggris, mandarin, Tamil dan Malay dan penduduknya menggunakan alih kode dalam suasana tertentu.

Alih kode dapat dijelaskan sebagai kemampuan seseorang dalam memilih bahasa yang sesuai dengan lawan tutur konteks situasional topik pembicaraan dan kemampuan berganti bahasa dalam suatu interaksi sesuai dengan aturan 
sosiolinguistik tanpa melanggar batasan tatabahasa tertentu. Alih kode juga mempunyai fungsi utama sebagai penanda identitas penutur misalnya untuk mengungkapkan jenis identitas kecanggihan atau otoritas. Bahasa Arab dan persia digunakan untuk menonjolkan identitas umat Islam di Indonesia bahasa Indonesia sebagai penanda nasionalitas dan persatuan. Fungsi sosial dan tekstual tersebut sangat penting sebagai ungkapan kepribadian dari masyarakat multikultural. Pengalihan kode bisa terjadi karena si pembicara merasa tidak puas atau tidak cukup untuk menjelaskan suatu tema dalam bahasa tertentu. Peralihan terjadi karena karena berubahnya situasi.

Rocky Gerung adalah salah satu pengamat politik yang sedang naik daun melalui berbagai media visual. Banyak tema diskusi dan presentasi yang dia ikuti, dan terlibat sebagai pembicara di berbagai tempat. Walaupun orang kampus lebih mengenal dia sebagai dosen filsafat, namun latar belakang pendidikan, cara pandang dan pendapatnya menyeberang ke berbagai wilayah pembicaraan tema diskusi, bahkan ke soal yang paling sensitif agama maka muncullah istilah kitab suci adalah fiksi yang menjadi perdebatan publik netizen persada nusantara. Sebagai seorang akademisi pemahaman filsafat politik yang mendasari dia berbicara adalah proses perbaikan dan provokasi yang ia sebut sebagai akal sehat. Rocky Gerung mulai kuliah dan menjadi aktifis di Universitas Indonesia dan orang kini mengenalnya sebagai pengamat politik yang muncul di berbagai media visual sebagai pembicara atau lawan debat dengan tema politik ekonomi dan lainnya.

Berdasarkan latar belakang di atas topik yang akan diambil adalah bahasa dan konsep politik: analisis alih kode dalam diksi debat dan presentasi pengamat politik Rocky Gerung. Perubahan pilihan kosa kata bahasa Inggris yang diungkapkan Rocky Gerung dalam debat adalah faktor yang menyebabkan alih kode. Diksi adalah sebuah pilihan kata yang tepat dan selaras (dalam penggunaannya) untuk mengungkapkan gagasan sehingga diperoleh efek tertentu (seperti yang diharapkan). Diksi memiliki beberapa fungsi sebagai menjadi lebih paham mengenai apa yang ingin disampaikan, membuat komunikasi menjadi lebih efektif, melambangkan ekspresi yang ada dalam gagasan secara verbal (tertulis atau pun terucap), membentuk ekspresi atau pun gagasan yang tepat sehingga dapat menyenangkan pendengar atau pun pembacanya.

Dalam penelitian ini peneliti mengobservasi dengan menyimak beberapa hasil presentasi dari media sosial yaitu YouTube dalam presentasi atau debat Rocky Gerung dalam membawakan tema. Rocky Gerung konsisten membawakan presentasinya menggunakan bahasa Indonesia dan pada saat tertentu beralih ke bahasa Inggris. Peneliti menyimak secara bebas dalam acara debat Rocky Gerung tanpa terlibat dalam peristiwa tutur tersebut karena memang objek penelitiannya berbentuk audiovisual yang dibentuk ke dalam teks tertulis. 
Peneliti menggunakan analisis alih kode dalam penelitian ini dan mengetahui penguasaan bahasa dan diksi yang dimiliki oleh Rocky Gerung dengan cara menghubungkan unsur-unsur yang terdapat dalam suatu bahasa ataupun beberapa bahasa yang berbeda.

\section{B. PEMBAHASAN}

Dalam perdebatan dan diskusi Rocky Gerung, kata-kata sisipan yang menjadi alih kode bahasa Inggris adalah berupa frasa bahasa Inggris yang umum, tetapi juga terkadang yang belum terkenal dan secara gramatikal benar. Rocky Gerung melakukan alih kode dalam bentuk frasa kata dan kalimat. Alih kode Rocky Gerung tampak dalam suasana santai. Pergantian bahasa atau berubahnya dari ragam santai ke ragam resmi atau juga ragam resmi ke ragam santai ini disebut peristiwa alih kode (Abdul chaer dan leonie: 2010). Rocky Gerung membentuk penggunaan istilah atau frasa yang singkat dan padat. Dalam acara debat tersebut bahasa Indonesia adalah sangat dominan dilakukan oleh Rocky Gerung. Namun pada beberapa kesempatan yang mengungkapkannya beberapa kata dan frasa atau bahkan kalimat dalam bahasa Inggris.

Berikut adalah hasil observasi secara audiovisual beberapa cuplikan kalimat dalam debat dan presentasi Rocky Gerung di berbagai media visual.

1. Korpus 1 . Tema debat tentang jalan toll.

“..Membelah keakraban warga negara.......coba kita lihat logic di belakangnya itu the other side of the story ......warung tegal tidak disinggahi oleh paspampres artinya tidak terjadi spill over economi buat mereka...banyak warung di brebes itu.....tidak dihampiri oleh rombongan presiden. Jadi selalu ada reverse logic dari setiap upaya untuk mempromosikan prestasi."

Rocky Gerung mengatakan the side of the story untuk mengungkapkan bahwa ada sisi lain dampak dari adanya jalan tol. Sisi negatifnya itu, dia mengatakan, tidak tersadap. Dia memilih kata spill over untuk menggambarkan penyebaran ekonomi secara luas, karena spill over bermakna tumpah, penyebaran ekonomi. Dia ingin menekankan makna yang padat dan dalam untuk penyebaran dan Kemajuan ekonomi masyarakat di bidang kewirausahaan dan bisnis yang luas dengan alih kode spill over. Reverse logic adalah alih kode untuk makna logika terbalik atau bersebrangan dengan logika yang ada.

2. Korpus 2. Cuplikan Seminar nasional di UIN Sunan Ampel Surabaya dengan tema eksistensi demokarsi pancasila dalam menghadapi tahun politik.

“..Eksistensi demokrasi pancasila dalam menghadapi tahun politik. Eksistensi dalam filsafat dinamakan kecemasan. Manusia itu ditakdirkan untuk exist karena dia satunya makhluk yang mempunyai kecemasan. 
Macan di-drive oleh instink untuk menerkam, manusia di-drive untuk cemas. Eksistensi orang yang menghadapi kecemasan radikal yang dicemaskan, apakah pancasila menjadi dasar pancasila, menghasilkan politik bermutu? saya mencemaskan. Kita cemas dengan infrastruktur pikiran kita yang dikendalikan seceara hegemonis oleh birokratis kampus oleh tertib kekuasaan."

Pada beberapa bagian Rocky Gerung mengucapkan kata exist yang artinya ada, drive yang dalam bahasa Indonesia adalah mendorong, mengendalikan dan menggerakan, dan dalam kalimat tersebut berbentuk kalimat pasif - $d i$ sehingga mengandung pengertian dikendalikan, diatur, digerakan. Dengan demikian tepat sekali dengan dikendalikan instink hewan menerkam, dengan kecemasan manusia bisa digerakan dan didorong. .

3. Korpus 3.

"...Goverment of reason through the goverment by the the people demokrasi dimaksudkan mengganti cara pemerintahan yang tidak berdasarkan akal. Mahkota keturunan, darah biru, demokrasi membatalkan hal itu. Orang yang terpilih dalam demokrasi seharusnya berakal sehingga bisa membedakan antara sopan santun yang juga dalam bahasa Indonesia disebut etika dan etics dalam pengertian demokrasi, mengatakan : anda tidak bermoral, moral cara mengaevaluasi perilaku berdasarkan prinsip etics bukan etika, moral dalam bahasa Indonesia moril semangat, sopan santun dalam demokrasi ketakjujuran untuk mengucapkan kritik...Too many cooks spoil the broth .."

Rocky Gerung menggunakan kalimat Goverment of reason through the goverment by the people tersebut untuk menekankan pentingnya Pemerintahan yang berakal sehat melalui rakyat. Dia memunculkan diksi kalimat Too many cooks spoil the broth sebagai terlalu banyak tukang masak "di istana." dalam penjelasannya untuk menggantikan makna terlalu banyak tukang masak merusak kaldu. Menurut peneliti, hal itu maksudnya adalah untuk menggambarkan kepemimpinan yang terlalu banyak ikut mengatur dan terlibat di belakang layar.

4. Korpus 4. Debat calon president 2019

“..Pak Jokowi bereaksi untuk hal yang keliru seharusnya lebih cepat membikin fact cheking faktanya apa. Pak Jokowi menghapal jumlah jumlah hektar tanahnya prabowo. Tapi keluar di tempat yang salah. Chek aja itu tanah liar apa legal. Kecepetan keluarnya besok jadi rame."

Rocky mengabil diksi fact checking untuk menekankan pentingnya pengecekan terhadap fakta di lapangan dalam debat tersebut. Menurut penulis 
alih kode tersebut adalah cara dia mengungkapkan kejengkelan, dan penekanan atas pentingnya pengecekan di lapangan masalah pertanahan.

5. Korpus 5. Acara debat calon presiden tahun 2019

“..Presiden itu nggak boleh mengekploitasi back mind pubic. Itu back mind public yang kadangkala itu populisme. Bisa semua orang merampok dimana mana. Ngapain dipaksa politik untuk mengembalikan tanah, dia mengembalikan karena dia mau jadi philanthropis bukan dipaksa oleh politik."

Dalam debat tersebut dia ungkapkan kata back mind public dan philanthropist untuk menggambarkan jalan pikiran, kata kata yang bagus di belakang, dan populer yang disampaikan kepada masyarakat, dan philanthropis, yang berarti banyak hartanya dan yang dermawanlah yang bisa memberikan tanah kepada pemerintah.

6. Korpus 6. Debat president 2019

“.......Jokowi jawabnya sudah ada feasibility tadi justru Pak Jokowi ditegur oleh bank dunia karena ...... public issues-nya timbul dulu atau pake tender. Dia pake bank dunia tapi tidak pake tender........Ngapain BUMN membikin anak perusahaan buat bersaing dengan swasta karena itu motivenya untuk menyingkirkan swasta karena itu ada captive market.....tetapi secara strtaegis terlihat pak jokowi itu di brief dengan data...

Dia menggunakan diksi feasibility yang berarti sebuah studi yang bertujuan untuk menilai kelayakan implementasi sebuah bisnis, misalnya keuntungannya. Public issues maksudnya adalah pemberitaan publik atau masalah publik. Captive market maskudnya adalah cara menahan, menawan, memenangkan pasar. Menurut penulis itu adalah pemasaran secara paksa. Brief berarti pengarahan, bimbingan secara cepat, dan singkat.

7. Korpus 7. Rocky gerung berdebat dengan tenaga ahli utama kantor staff kepresidenan.

“...Kalo dengan undang undang haknya justru dibatalkan diusir malahan, itu artinya penjelasan ini tidak fit and proper dengan dasarnya. .....indeks sahamnya turun akibatnya persepsi tentang investasi juga memburuk itu sebetulnya back fire effect kekonyolan pengaturan di ruang publik."

Dia mengomentari tentang kebebasan berpendapat, dan menyisipkan diksi fit and proper untuk menegaskan bahwa hal itu sudah sesuai, cocok, tidak dilarang dan selaras, benar menurut undang -undang dasar. Diksi back fire efect 
dia gunakan untuk menggambarkan makna dampak terburuk akibat pengaturan yang salah.

8. Korpus 8. Debat politik dengan Pengamat politik Adian

“...Saya berusaha untuk tidak menyebut dungu tapi paktanya bertambah terus... dia berusaha untuk demagog menghentikan pembicaraan saya supaya tidak terjebak oleh logic yang palsu."

Kata demagog adalah diksi yang memiliki makna luas dalam bahasa Indonesia yaitu penghasutan terhadap orang banyak dengan kata-kata yang dusta untuk membangkitkan emosi rakyat. Oleh sebab itu, penggantian dengan diksi demagogue adalah menghemat pilihan kata dan karena lawan bicara dianggap sudah intelek dan cerdas, maka dia memilih diksi tersebut.

9. Korpus 9. Talk show di kampus

“...Ada semacam gangguan pencernaan pada bangsa ini sehingga mengalami konstipasi susah buang air besar, artinya ada gangguan di dalam lambung. Sebelum uni sovyet runtuh roma runtuh abad ke 3. Utopia tomas more bekas pastor pemikir sosial, Dunia itu harus punya harus punya harapan, eu bagus topos artinya tempat. 500 tahun setelah buku itu ditulis ada distopia, ketegangan, dunia yang buruk, utopia pulau penuh tempat berekreasi, penuh harapan...kita hidup dalam republic of fear dengan membuka kotak pandora punya konseksensi tetapi kita memahami diri sendiri.

Konstipasi adalah istilah yang sudah diadopsi kedalam bahasa Indonesia yang artinya sembelit atau susah buang air besar dan dia ucapkan untuk membuat analogi, perbandingan, dan menekankan maksud dan tujuan lebih kuat dalam kalimat tersebut. Demikian juga kata utopia adalah diksi sebagai analogi, perbandingan, untuk menguatkan makna harapan, tempat yang lebih baik. Republic of fear adalah diksi untuk menjelaskan keadaan bangsa yang penuh ketidaktahuan karena tidak tahu apa kekurangan, keburukan, dan tidak mau membuka kotak pandora (yang berisi kekacauan kejahatan, kekurangan yang dengan membukanya maka diketahui realitasnya apa yang harus diperbaiki dan masalahnya). Karena tidak tahu dan takut sehingga tidak mampu memperbaiki diri.

10. Korpus 10. Pembicara pada acara konsolidasi Prasasti, Prabowo Sandi.

“...Anggota DPR watch dog karena dia dipilih untuk menggonggongi pemerintah supaya pemerintah tidak jadi otoriter.....Ada under current politik arus bawah yang tidak dibaca kekuasaan karena justru dikontrol maka tidak beredar di atas permukaan tapi di bawah black market of power.... 
Dia mengatakan watch dog untuk menggambarkan, menekankan fungsi DPR lebih kuat. Dengan analogi tersebut fungsi DPR menjadi tegas sehingga jelas tujuannya, dan apa perannya bersama pemerintah. Under current politics adalah diksi untuk menjelaskan kegiatan politik yang tidak terbaca oleh lawan dan cenderung menggunakan kekuatan dengan cara apapun bahkan mungkin yang tidak baik (black market of power), atau menyalahi aturan.

11. Korpus 11. Debat di televisi: Kitab suci adalah piksi.

“... Dan itu sebetulnya permulaan yang buruk karena waktu kita sebut fiksi di kepala kita adalah fighting fiction itu kata benda yaitu literatur... tapi karena dia diucapkan dan satu forum politik maka dianggap sebagai buruk. Sangat bagus dia adalah energi untuk mengaktifkan imajinasi itu fungsi dari fiksi dan kita hidup dalam dalam dunia fiksi lebih banyak daripada dalam dunia realitas. Fiksi lawannya realitas bukan fakta Jadi kalau anda bilang itu fiksi lalu kata itu jadi peyoratif itu artinya kita menginginkan anak-anak kita tidak lagi membaca fiksi karena udah 2 bulan ini kata Fiksi itu menjadi kata yang buruk kitab suci fiksi atau bukan.... Saya pakai definisi Fiksi itu mengaktifkan imajinasi kitab suci itu adalah fiksi karena belum selesai belum tiba itu Babad Tanah Jawi itu fiksi ....fungsi dari fiksi untuk mengaktifkan imajinasi menuntun kita untuk berfikir lebih imajinatif.... anda percaya pada fiksi dan anda dituntun oleh kepercayaan itu....Kenapa Anda abaikan sifat fictional dari kitab suci itu...dituntun oleh dalil-dalil dalam kitab suci bukan saya prediksi itu... Kalau saya bilang kitab suci itu fiktif besok di penjara tapi kalau itu fiksi argumen terhadap eskatologi dari kitab suci. ...karena selama ini kata Fiksi itu dibebani oleh kebohongan salah, Fiksi itu bohong, bohong itu fiktif dalam bahasa Indonesia kita bilang fiktif artinya itu apa fiktif bohong. Tapi fiksi energi untuk tiba ke teloz yang di depan itu kita ingin tiba di telos ujung dari kitab suci itu adalah harapan janji itu sifatnya fiksi. baik. ....Fiksi itu kreatif sama seperti orang beragama kreatif dia menunggu...dia menunggu telos nya tuh anda ucapkan doa sebetulnya Anda masuk dalam energi fiksional kan ada harapan dengan untaian doa itu Anda akan tiba di tempat yang indah begitu fiksi bekerja.....di dalam agama Fiksi itu adalah keyakinan di dalam literatur fiksi adalah energi untuk mengaktifkan imajinasi sama orang berdoa dan baca novel kimianya sama di dalam tubuh sama jenis hormon yang diproduksi sama itu pengantar untuk menertibkan kekacauan publik."

Menurut pendapat penulis, Dia menjelaskan makna diksi fiksi dari sudut filsafat yang akhirnya berujung pada kata baik dan positif karena ada kata-kata kunci yang ia maksud yaitu mengaktifkan imajinasi, menuntun untuk berpikir, dituntun oleh kepercayaan, dalil-dalil, keyakinan, kreatif, harapan, dan doa. 
12. Korpus 12.

“...Secara historis, kecemasan oleh publik dunia mengapa Eropa masuk dalam jebakan kedunguan.....eropa itu mengambil jalan buntu karena pemimpinnya adalah the mediocre orang yang separo separo, separo punya pengetahuan tapi ingin pamer separo kekuasaan tapi arogan, separo soleh tapi ingin masuk surga, diantara separo ini bangsa ini mengalami keterpurukan. Kita melakukan konfrontasi secara kualitatif..."

Dia mengungkapkan kata the mediocre, istilah yang memang sebetulnya sudah umum dan digunakan untuk menjelaskan karakter pemimpin di eropa yang berada pada tingkat biasa-biasa saja, atau pertengahan yang ia sebut dengan istilah separo-separo. Dengan istilah the mediocre dia bermaksud menekankan kata tersebut lebih simpel, gampang diingat, dan bermakna.

13. Korpus 12. Membahas tentang ektp

“...Novanto hanya nunjuk-nunjuk berarti dia whistler blower bukan justice collaborator. ghots fleet armada hantu yang akan ditunggangi orang.. Ada pain killer agar demokrat tidak terlalu terpanggang."

Dia mengatakan whistler blower untuk memberi makna sebagai pelapor, dan justice collaborator sebagai kolaborator keadilan. Ghost fleet yang dimaksud adalah tunggangan politik yang dipakai para politisi yang membahayakan dan merugikan sehingga dianalogikan dengan menakutkan. Tunggangan tersebut bisa berupa partai, dan lain-lain. Pain killer dia ucapkan untuk mengganti makna penghilang rasa agar tidak terlalu sakit, penghibur dan pengobat agar tidak terlalu terluka dalam kehidupan politik.

\section{KESIMPULAN}

Berdasarkan hasil analisis dan pembahasan hasil penelitian ini, maka penulis mengambil beberapa kesimpulan pada diksi alih kode Rocky Gerung sebagai berikut:

1. Diksi alih kode Rocky Gerung cara berkomunikasi yang indah karena transaksi berbahasa menjadi tidak membosankan dan menarik untuk didengar.

2. Diksi alih kode Rokcy Gerung yang berupa frasa dan kalimat muncul memiliki tujuan sebagai analogi, untuk menggambarkan keadaan yang sebenarnya dengan kalimat lain yang memiliki analogi sama dengan yang diperbincangkan.

3. Beberapa diksi Rocky Gerung memiliki rasa bahasa yang biasa saja, artinya diksi tersebut dalam pembicaraan bahasa Indonesia tidak perlu diganti 
kedalam bahasa Inggris, namun Rocky Gerung memilihnya bahasa Inggris untuk menguatkan rasa dan gampang diingat.

4. Rocky Gerung membuat ungkapan yang efektif dan hemat dalam pengambilan diksi alih kode karena dalam bahasa Indonesia untuk mengungkapkan makna tersebut harus dengan kalimat yang panjang, yang dengan diksi alih kode cukup satu dua kata.

5. Rocky Gerung melakukan alih kode dengan tujuan menekankan, dan mempertahankan warna asli bahasa tersebut misalnya dengan diksinya the mediocre yang dalam bahasa Indonesia akan menjadi bias bila diterjemahkan.

6. Rocky Gerung juga mengungkapkan diksi alih kode untuk menunjukkan kejengkelan, kemarahan kepada lawan debat sehingga memilih kata yang bisa mewakili pikirannya dengan prasa tersebut.

7. Rocky Gerung berbicara dan memilih diksi alih kode dengna memperhatikan kejiwaan agar makna diksi yang diucapkan lebih mengena dan mendalam.

8. Rocky Gerung memilik diksi alih kode dengan suka tidak suka artinya sebetulnya itu biasa namun ia ungkapkan dengan diksi bahasa Inggris sambil tertawa dan bercanda.

9. Rocky Gerung mengambil diksi alih kode sebagai argumentasi untuk menarik simpatik pendengar sehingga menjadi menarik, mudah diingat dan dihapal.

10. Rocky Gerung memang memiliki bakat berbahasa dan pengetahuan yang cukup, sesuai latar belakang pendidikan yang sering berganti ganti yang sedikit banyak mempengaruhi cara berpikir dan pengetahuannya.

\section{REFERNSI}

Abdul Chair, Leonie Agustine. 2010. Sosiolinguistik Perkenalan Awal (Revisi) Jakarta: PT Rineka Cipta.

Alwasilah, A. Chaedar. 1985. Sosiologi Bahasa. Bandung: Angkasa

Habibi, M. 2018. Bahasa dan konsep Agama: Stud Alih Kode dalam Ceramah Agama KH Jamaludin. Jakarta: AlTuras.

https://www.youtube.com/watch?v=_Q3EUB91EpQ

https://www.youtube.com/watch?v=6bjHOmtHSaY

https://www.youtube.com/watch?v=B6f_4uaKqUM\&t=16s

https://www.youtube.com/watch?v=EOkfM6mf3RI

https://www.youtube.com/watch?v=F4VpJ4yaTyk

https://www.youtube.com/watch?v=JE4DIDIPsSo\&t $=63 \mathrm{~s}$

https://www.youtube.com/watch?v=NflX2UuRuKc

https://www.youtube.com/watch?v=OhZ-RsNBcqA

https://www.youtube.com/watch?v=p9tUUTxf41M

https://www.youtube.com/watch?v=TrXBzJ1Hp4A

https://www.youtube.com/watch?v=ystUnSqVnvA\&t=57s

Lapasau, Merry; Arifin, EJ.2016. Sosiolinguistik. Jakarta: Pustaka Mandiri.

Ronald Wardhaugh. 2002. An introduction to Sociolinguistics. Massachusett: Blackwell Publishers Inc. 